\title{
Influences of Groove Angles and Filler Metals on 304L Stainless Steel to AISI 1040 Carbon Steel Dissimilar Joint by Gas Tungsten Arc Welding
}

\author{
Eriek Wahyu Restu Widodo ${ }^{1, *}$, Vuri Ayu Setyowati ${ }^{1}$, Suheni ${ }^{1}$, and Ahmad Rilo Hardianto $^{1}$ \\ ${ }^{1}$ Department of Mechanical Engineering, Faculty of Industrial Technology, Institut Teknologi Adhi \\ Tama Surabaya, 60117 Surabaya, Indonesia
}

\begin{abstract}
Dissimilar joint commonly applied on pressure vessel application in power plan field as joining between the tank and the stanchion of pressure vessel. This paper presents the investigations carried out to study the influence of groove angles and filler metals on $304 \mathrm{~L}$ Stainless Steel to AISI 1040 Carbon Steel dissimilar joints. Gas Tungsten Arc Welding with 120 A of current was used on this research, joined the two different metals. The $30^{\circ}, 45^{\circ}$, and $60^{\circ}$ were used in this welding as parameters of V-groove angles. ER 308L-16 filler metal of stainless steel and ER 70S-6 filler metal of carbon steel were used as filler metals. Tensile test was conducted to obtain tensile strength of joint and to analysis of the effect of the welding parameters to the mechanical properties. The highest tensile strength was obtained from the $60^{\circ}$ groove angle using ER $308 \mathrm{~L}-16$ filler metal of $614.54 \mathrm{MPa}$. In the other hand, $45^{\circ}$ groove angle using ER 70S-6 filler metal obtained the lowest tensile strength of $578.66 \mathrm{MPa}$. The joining process of dissimilar welding using ER 308L-16 filler metal, filler metal for stainless steel, has obtained the highest tensile strength with wider groove angle as well.
\end{abstract}

Key words: Dissimilar welding, ER 308L-16, ER 70S-6, welding process.

\section{Introduction}

Joining of dissimilar metal combinations are employed in different applications requiring a certain special combination of properties as well as to save cost incurred towards costly and scarce materials [1]. Stainless steels are widely used in both industrial production and dailylife due to their anti-corrosion ability. Owing to high-cost and shortage in $\mathrm{Cr}$ and $\mathrm{Ni}$ resources, there has been an increasing interest in developing low-cost stainless steels for decades [2]. Austenitic Stainless Steel (ASS) AISI 304L is being extensively used in the field of defense and nuclear science due to its excellent corrosion resistance in seawater environment [3]. Stainless steel 304L has lower carbon than stainless steel 304, therefore stainless steel 304L is easier to be welded. This property of ASS 304L is due to the

* Corresponding author: eriek@itats.ac.id 
presence of molybdenum, which prevents chloride corrosion. It also has a low carbon content due to which the wear and friction properties are improved and lower susceptibility to intergranular corrosion $[4,5]$.

In a nuclear water reactor, dissimilar metal welds are employed to connect the low alloy steel reactor pressure vessel and stainless steel pipe systems [6, 7]. Joining of carbon steel to stainless steel can combine the advantages of both metals and is full of promise in these field. However, it is of great difficulty to obtain sound joint of dissimilar metal between carbon steel and stainless steel due to the differences in chemical compositions and thermal physics properties [8]. The high temperature experienced in fusion welding process of carbon steel to stainless steel can lead to the inevitable formation of martensite [9] and the decarburized zone, which are both responsible for the deterioration of mechanical properties of the joint [8].

This paper presents the studies on AISI 304L and AISI 1040 dissimilar metal welded by Gas Tungsten Arch Welding (GTAW). The 304L Stainless Steel and AISI 1040 carbon steel were welded by GTAW with 120 A of current and V-groove joining with various angle parameters. The parameters of welding on this research consist of groove angles and filler metals. The research was conducted on mechanical property of joining using tensile test and microstructure characterization.

\section{Experimental}

This experiment was conducted using Miller MaxStar 200SD GTAW. The welding was operated by $120 \mathrm{~A}$ of current and V-groove of joining materials. The base metals employed in this research are 304L stainless steel and AISI 1040 low carbon steel, and their composition was shown in Table 1 . Both of base metals had a thickness of $12 \mathrm{~mm}$ sheet which was butt joint welded for all specimens.

Table 1. The composition of base metals (\%).

\begin{tabular}{|c|c|c|c|c|c|c|c|}
\hline Element & Fe & C & Mn & Si & Cr & Cu & Ni \\
\hline 304L SS & 70.780 & 0.025 & 1.140 & 0.410 & 18.40 & 0.180 & 8.190 \\
\hline AISI 1040 & 99.10 & 0.40 & 0.39 & 0.11 & 0.02 & 0.02 & 0.016 \\
\hline
\end{tabular}

The groove angles which used in this study were $30^{\circ}, 45^{\circ}$, and $60^{\circ}$, they were used as angle of $\mathrm{V}$-groove joining with $1 \mathrm{~mm}$ of welding gap. The ER $308 \mathrm{~L}-16$ filler metal for 304L stainless steel and ER 70S-6 filler metal for AISI 1040 carbon steel were used in every single dissimilar joint. The diameter of filler metal are $11.43 \mathrm{~mm}$ and $1.59 \mathrm{~mm}$ for ER 70S-6 and ER 308L-16 respectively. The welding process was conducted by 12 layers for all of specimens. The composition of ER 308L-16 and ER 70S-6 filler metals were shown in Table 2.

Table 2. The composition of ER 308L-16 (AWS A5.9) and ER 70S-6 (AWS A5.18) (\%).

\begin{tabular}{|c|c|c|c|c|c|c|c|c|c|c|}
\hline Filler & $\mathbf{C}$ & $\mathbf{S i}$ & $\mathbf{M n}$ & $\mathbf{P}$ & $\mathbf{S}$ & $\mathbf{C r}$ & $\mathbf{M o}$ & $\mathbf{N i}$ & $\mathbf{V}$ & $\mathbf{C u}$ \\
\hline \multirow{2}{*}{ ER 308L-16 } & 0.03 & 0.3 to & 1.0 to & 0.03 & 0.03 & 19.5 to & 0.75 & 9.0 to & & 0.75 \\
& $\max$ & 0.65 & 2.5 & $\max$ & $\max$ & 22.0 & $\max$ & 11.0 & - & $\max$ \\
\hline \multirow{2}{*}{ ER 70S-6 } & 0.06 to & 0.80 to & 1.40 to & 0.025 & 0.035 & 0.15 & 0.15 & 0.15 & 0.03 & 0.50 \\
& 0.15 & 1.15 & 1.85 & $\max$ & $\max$ & $\max$ & $\max$ & $\max$ & $\max$ & $\max$ \\
\hline
\end{tabular}

After welding process has finished, the next step was tensile strength testing and microstructure characterization. In order to observe the microstructure under the optical microscope, specimens were prepared according to the standard procedures. The tensile strength was carried out using universal tensile test machine to specimens of tensile test 
which was prepared according to the standard specimen of tensile test (ASME IX) as shown in Figure 1.

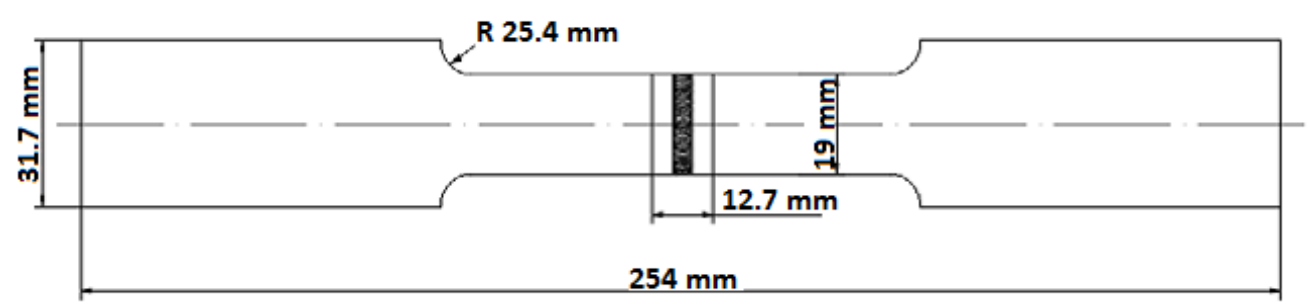

Fig. 1. Specimen of tensile test (ASME IX).

\section{Result and Discussion}

\subsection{Mechanical Properties}

The tensile strength of dissimilar welding on this research is presented in Table 3 and Figure 2. The tensile test's result shown the breaking part of joint for all of the spesimens were located on the weld metal. That was caused by the precipitation of carbide from iron as shown in Figure 5, Figure 6 and Figure 7, which formed nearby weld metal and HAZ. The tensile strength of all joint was conducted on groove angle and filler metals parameters. The highest tensile strength of dissimilar welding specimens was obtained by dissimilar welding using ER 308L-16 filler metal and $60^{\circ} \mathrm{V}$-groove angle of $614.54 \mathrm{MPa}$. The highest tensile strength was obtained up to $614.54 \mathrm{MPa}$, while the lowest was $304 \mathrm{~L}$ stainless steel base metal about $564 \mathrm{MPa}$.

The elongation is an ability of material to be elongated when the material is given a load, as known as ductility of material. Elongation is related to the tensile strength. Material with a high tensile strength is always has a high elongation, that means the material has a good ductility. The highest elongation was obtained by joining using ER 308L-16 filler metal with $60^{\circ} \mathrm{V}$-groove angle of $23.89 \%$. It was linear to the highest tensile strength of the same filler metal and groove angle for this dissimilar welding. The higher tensile strength, the higher elongation was obtained. That was indicating the joint with both high strength and elongation can be successfully obtained from this dissimilar joint.

In the other hand, joining using ER 70S-6, filler metal for carbon steel, was obtained lower tensile strength and elongation than using ER 308L-16 filler metal. It occurred due to ER 70S-6 filler metal has higher carbon content that indicating the decreasing of tensile strength and elongation of joint. It means that higher carbon content of filler metals resulting of more precipitation of carbides in the stainless steel. Table 3 shown that wider groove angles of joining resulting of the increasing tensile strength and elongation as figured in Table 3. Figure 2 shown the increasing of tensile strength was resulted by wider of the groove angles for both of filler metals parameters. 


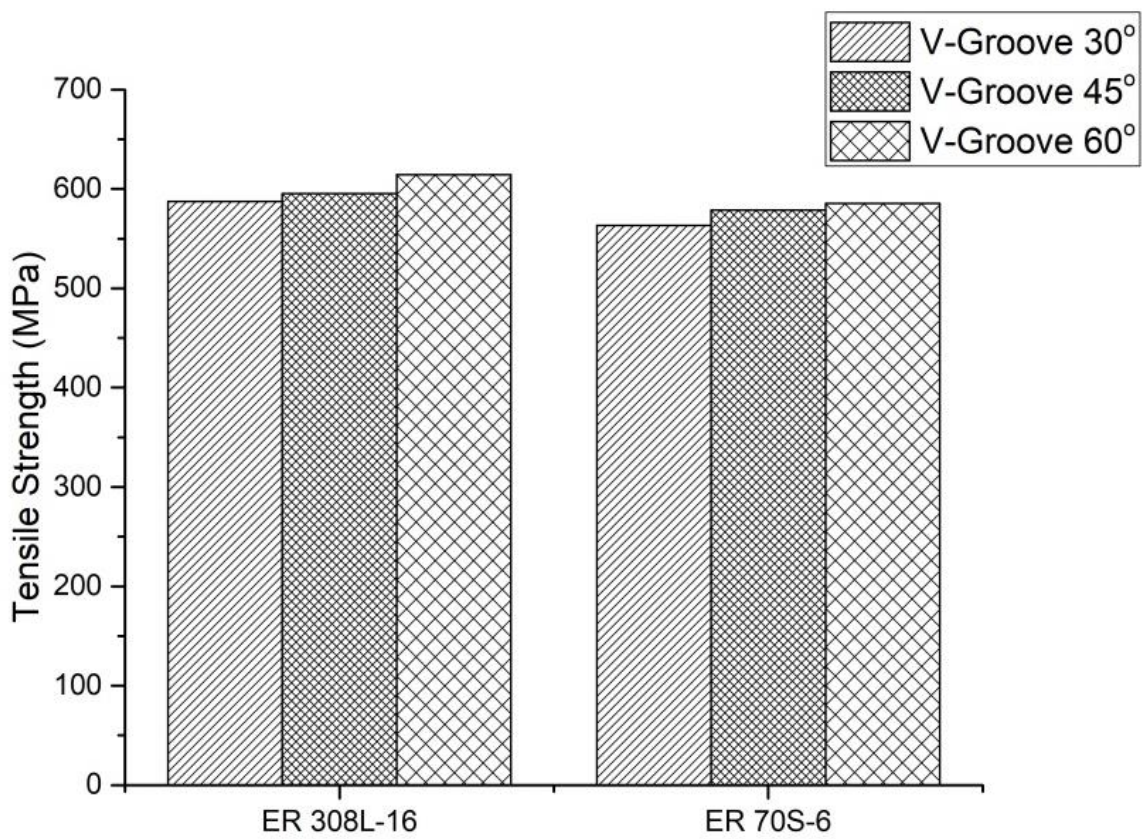

Filler Metals

Fig. 2. Tensile strength of dissimilar welding using groove angle and filler metals parameter.

Table 3. Tensile test of dissimilar welding 304L Stainless Steel to AISI 1040 Carbon Steel.

\begin{tabular}{|c|c|c|c|c|c|}
\hline $\begin{array}{c}\text { Filler } \\
\text { Metals }\end{array}$ & $\begin{array}{c}\text { Groove's } \\
\text { Angles ( }\end{array}$ & $\begin{array}{c}\mathbf{A}_{\mathbf{0}} \\
\left(\mathbf{m m}^{\mathbf{2}} \mathbf{)}\right.\end{array}$ & $\begin{array}{c}\text { Yield Strength } \\
\mathbf{( M P a )}\end{array}$ & $\begin{array}{c}\text { Ultimate Tensile } \\
\text { Strength (MPa) }\end{array}$ & $\begin{array}{c}\text { Elongation } \\
(\mathbf{\%})\end{array}$ \\
\hline \multirow{3}{*}{ ER 308L-16 } & 30 & 240.1 & 516.45 & 587.26 & 20.65 \\
\cline { 2 - 6 } & 45 & 240.21 & 528.7 & 595.31 & 21.72 \\
\cline { 2 - 6 } & 60 & 240.83 & 531.5 & 614.54 & 23.89 \\
\hline \multirow{3}{*}{ ER 70S-6 } & 30 & 239.59 & 500.86 & 563.46 & 17.10 \\
\cline { 2 - 6 } & 45 & 240.21 & 516.22 & 578.66 & 18.25 \\
\cline { 2 - 6 } & 60 & 240.83 & 519.04 & 585.98 & 19.98 \\
\hline
\end{tabular}

\subsection{Microstructure Analysis}

Microstructure of dissimilar welding 304L stainless steel to AISI 1040 carbon steel was observed under the optical microscope to study the differences of weld metal, HAZ, and weld metal region and also the phases forming for each filler metals parameters. Dissimilar joining using ER 70S-6 filler metal for carbon steel shows the different region that formed in Figure 3(a). Precipitation of carbides was formed in the border region of HAZ and base metal 304L stainless steel was obtained by the higher carbon content of filler metal. In weld metal of this joint was formed pearlite and ferrite phase that obtained by high carbon content from filler metal of carbon steel as shown in Figure 3(b). While HAZ region in the border area of weld metal and base metal AISI 1040 carbon steel was narrower than HAZ region in the border area of weld metal and base metal 304L stainless steel as shown in Figure 3(c), this phenomena was caused by carbon content of filler metal almost equal with base metal AISI 1040, contain of high carbon.

Figure 4(a) shown the forming of austenite phase that appearing in the border area of HAZ and 304L stainless steel, while the weld metal also appearing austenite phase and a little precipitation of carbides as shown in Figure 4(b). The 304L stainless steel and ER 
308L-16 filler metal have a reduced carbon content of 0.03 wt.\% or lower which limits the precipitation of carbides [10]. HAZ which located between weld metal and base metal AISI 1040 had a narrow area due to low carbon content as shown in Figure 4(c). Carbon content was kept in low to avoid the formation of precipitation of carbides in the joining of 304L stainless steel. Precipitation of carbides from the joint using ER 308L-16 is caused of low carbon content from the carbon steel filler metal.

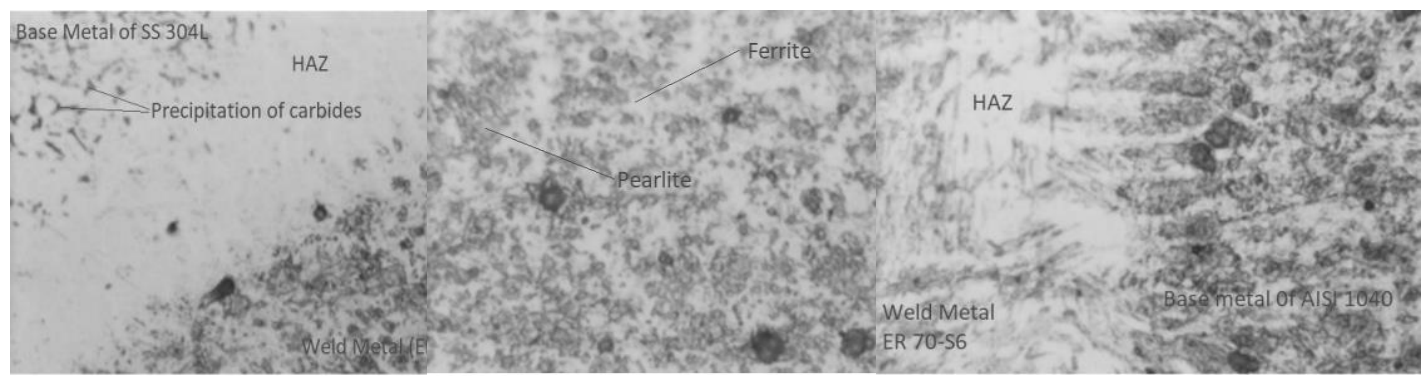

(a)

(b)

(c)

Fig. 3. Microstructure of dissimilar welding using ER 70S-6 filler metals of carbon steel for (a) HAZ and base metal 304L stainless steel, (b) weld metal, and (c) HAZ and base metal AISI 1040.

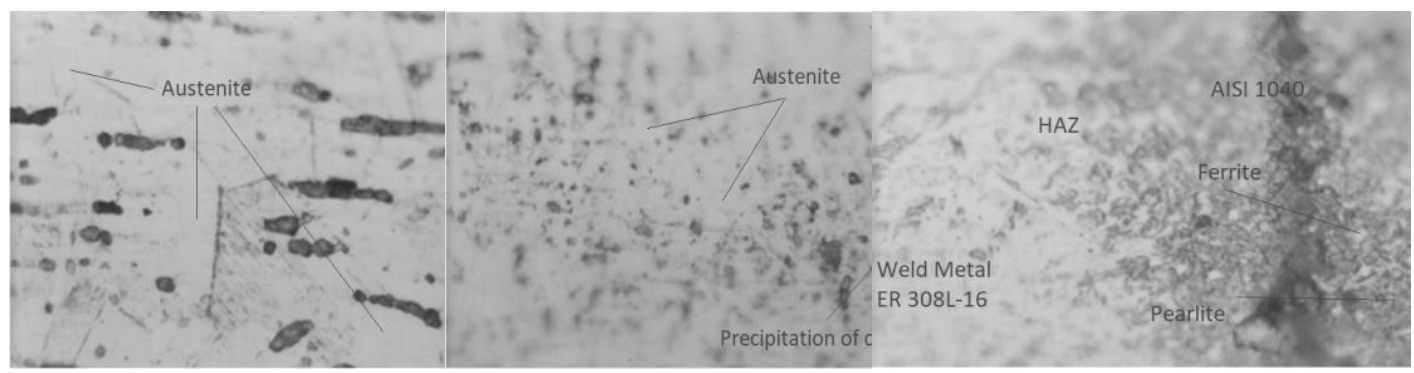

(a)

(b)

(c)

Fig. 4. Microstructure of dissimilar welding using ER 308L-16 filler metals of stainless steel for (a) HAZ and base metal 304L stainless steel, (b) weld metal, and (c) HAZ and base metal AISI 1040.

The precipitation of carbide was formed nearby weld metal and HAZ for both of the filler metals. The carbide was formed by iron that proved by EDAX and XRD analysis. The iron content according EDAX analysis was about $66 \%$ to $96 \%$, while chromium was about $2 \%$ to $17 \%$, as shown in Figure 5 and Figure 6 . The EDAX data were supported by XRD analysis as shown in Figure 7, as shown that iron had the highest intensity in the graph. Therefore, carbide from iron was formed iron carbide called as cementite.

\subsection{Macrostructure Characterization}

Macrostructure of dissimilar welding was investigated by etching process that obtained the difference area of joint. There are three regions of joining consist of base metal, HAZ, and weld metal. These region were shown by the different etching liquid, Nital for carbon steel and Aqua Regia for stainless steel. Figure 8 shown different region of these three regions of weld metal, HAZ, and base metal clearly. The narrowest angle of groove has obtained the widest HAZ because small surface area caused slower heat transfer. 


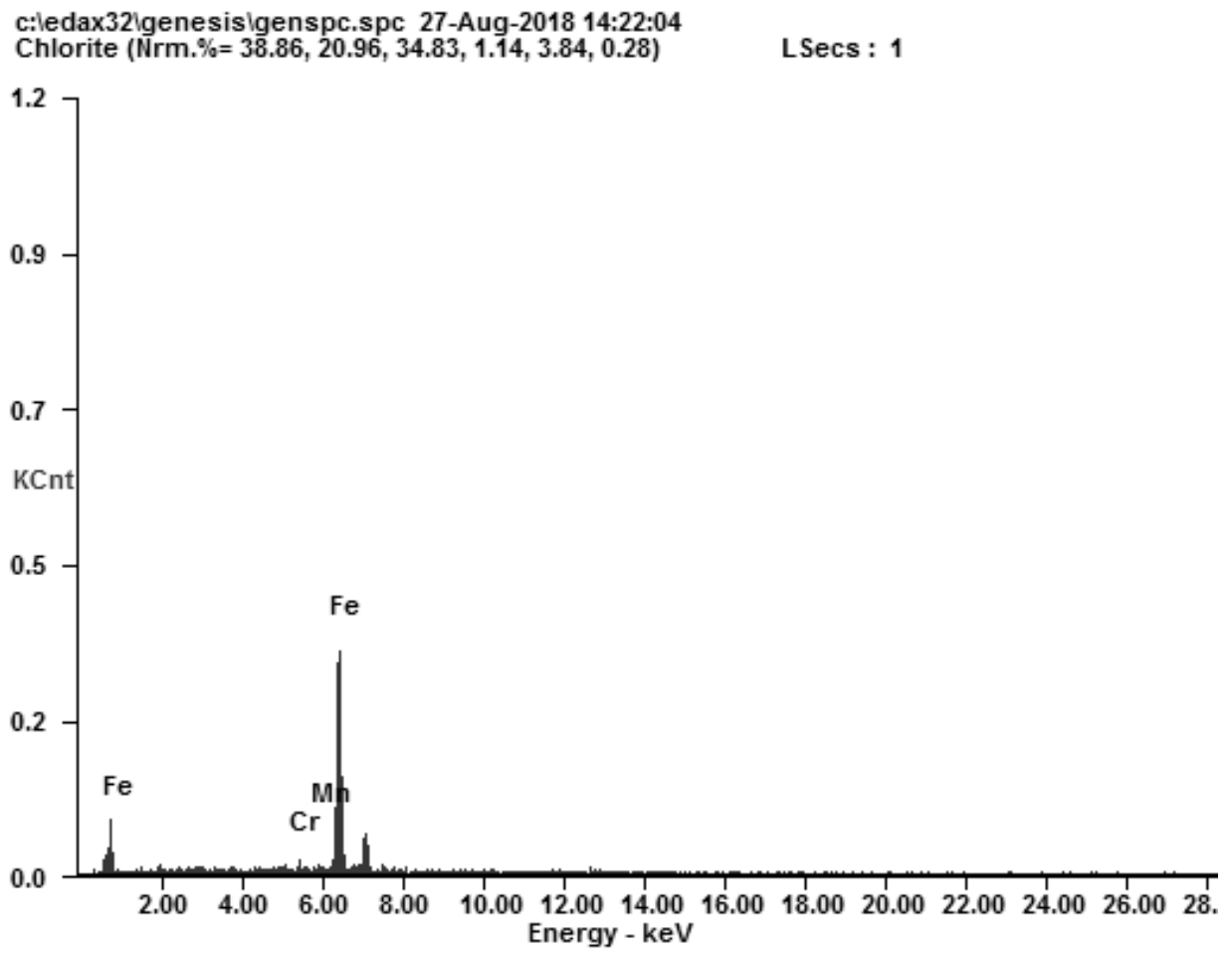

c:ledax32lgenesisigenspc.spc 27-Aug-2018 13:47:33

Chlorite (Nrm.\%=38.86, 20.96, 34.83, 1.14, 3.84, 0.28)

LSecs : 1

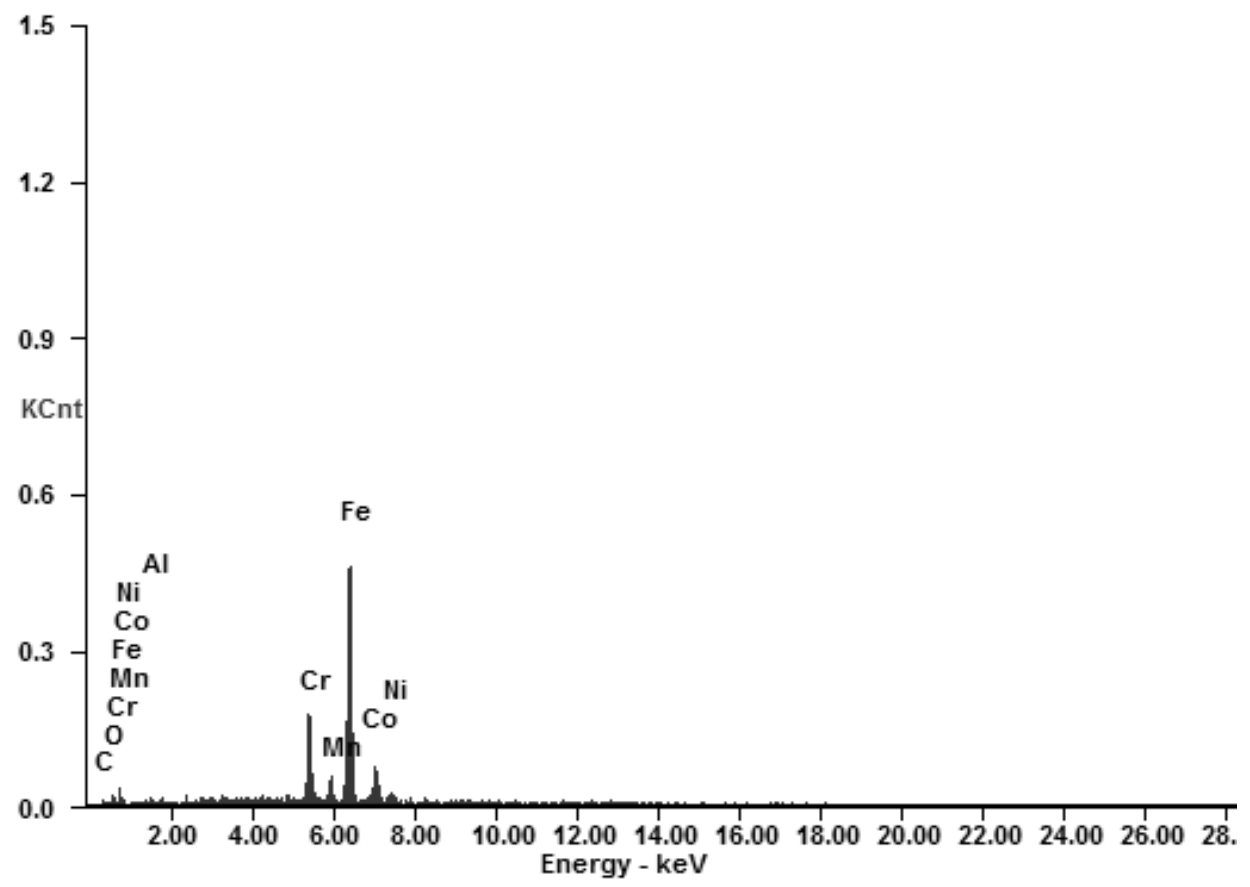

Fig. 5. EDAX analysis of ER 308L-16 filler metal of stainless steel. 
c:ledax32lgenesisigenspc.spc 27-Aug-2018 14:24:38

Chlorite (Nrm.\%=38.86, 20.96, 34.83, 1.14, 3.84, 0.28)

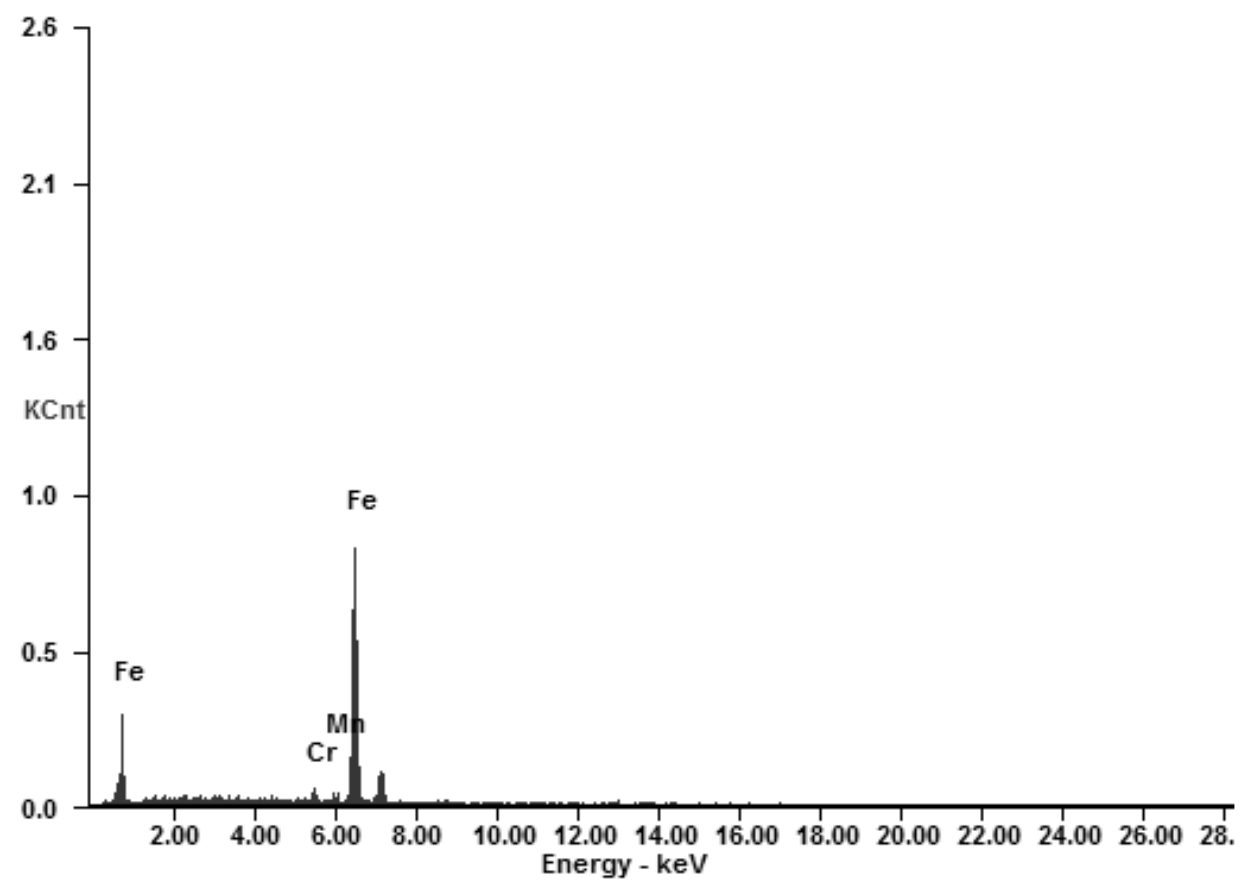

c:ledax32lgenesisigenspc.spc 27-Aug-2018 14:27:30

Chlorite (Nrm. $\%=38.86,20.96,34.83,1.14,3.84,0.28)$

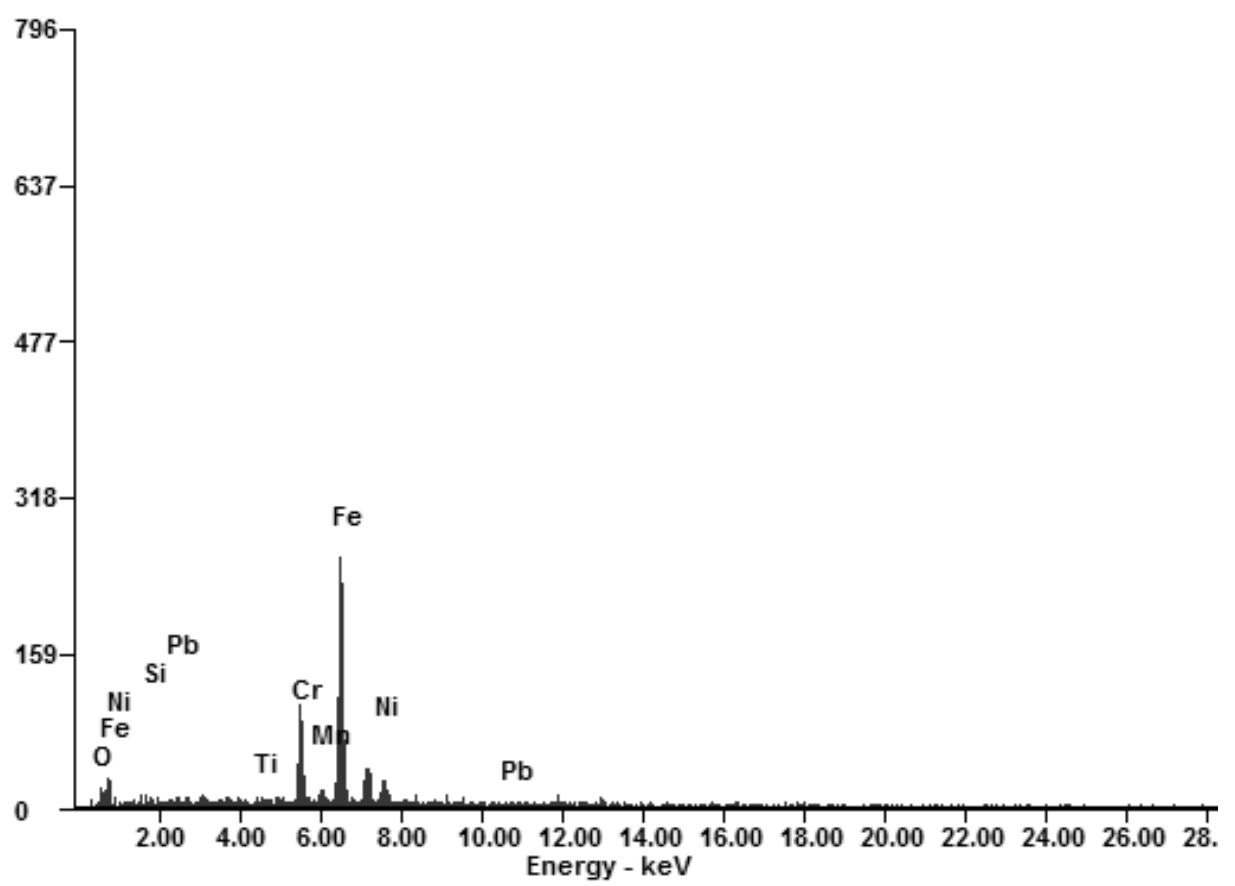

Fig. 6. EDAX analysis of ER 70S-6 filler metal of carbon steel.
LSecs : 1 


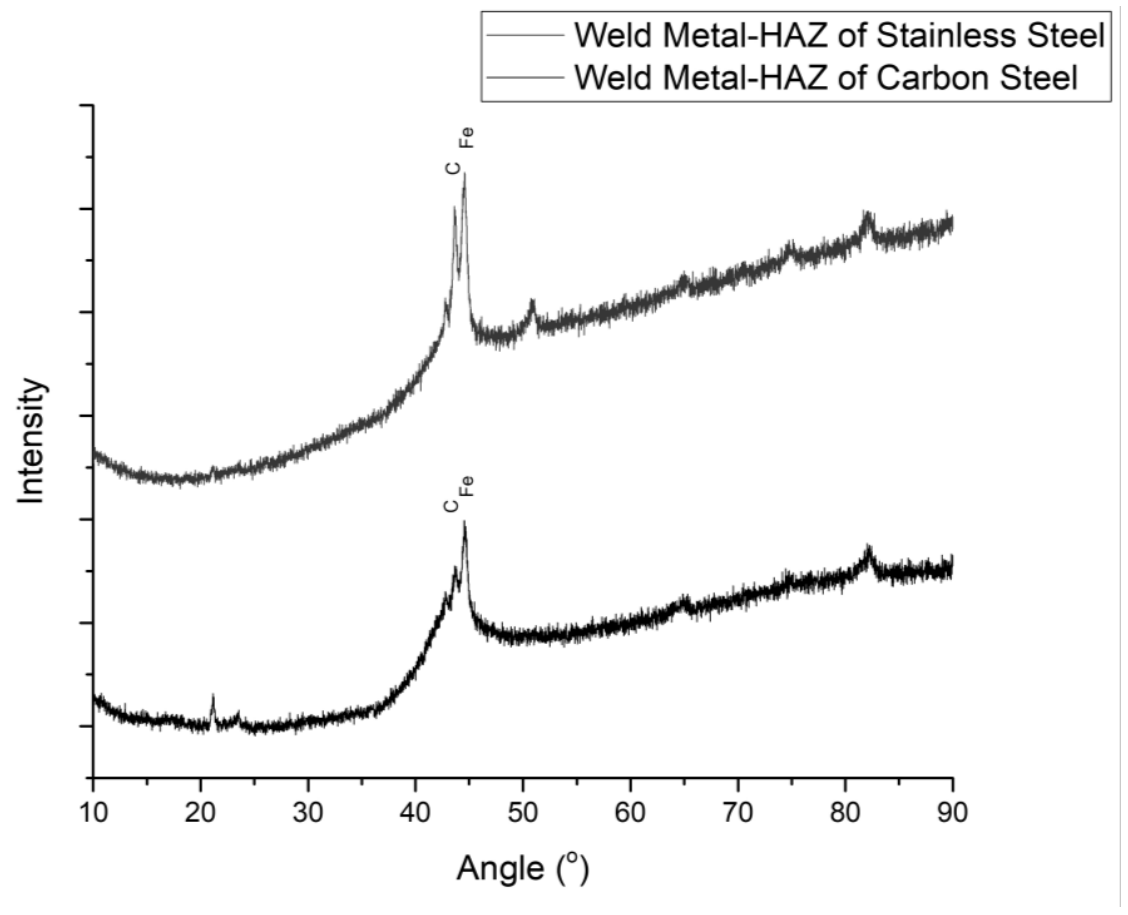

(a)

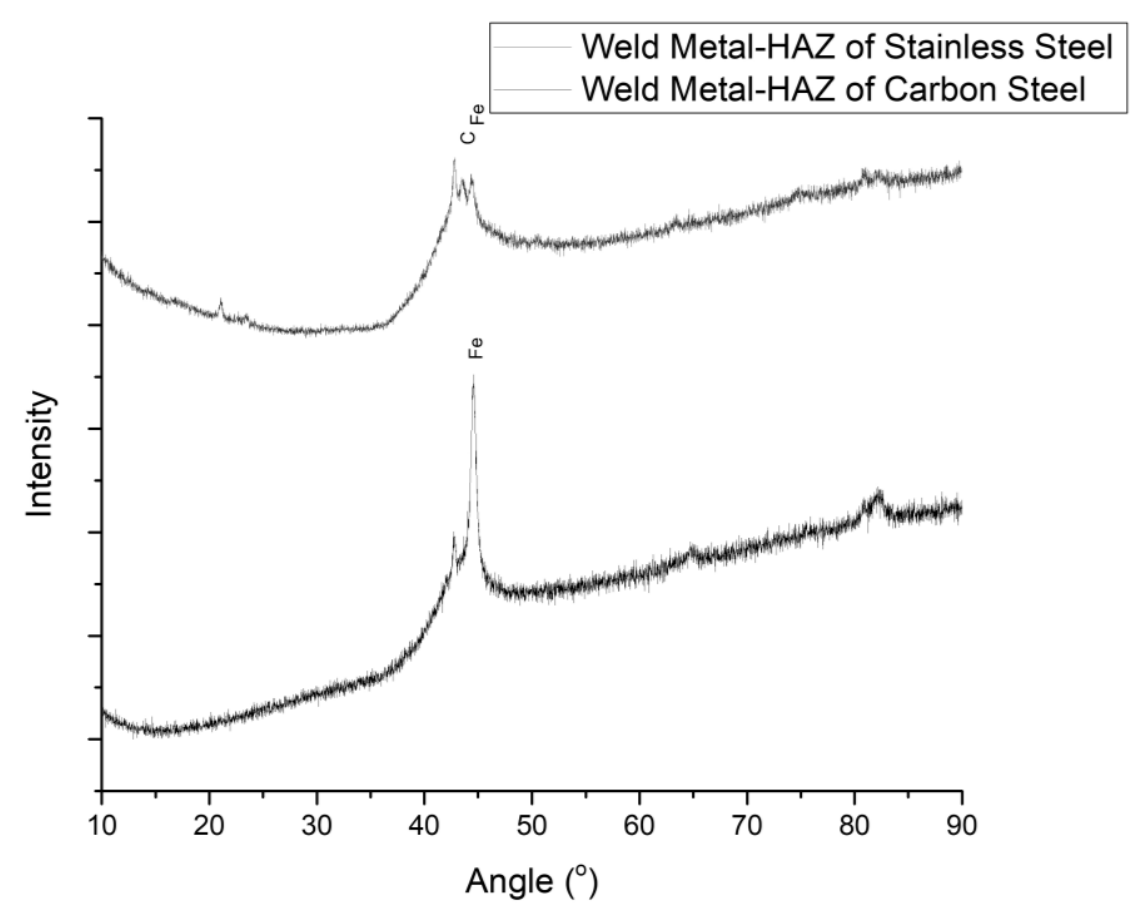

(b)

Fig. 7. XRD analysis of (a) ER 308L-16 filler metal of stainless steel and (b) ER 70S-6 filler metal of carbon steel. 


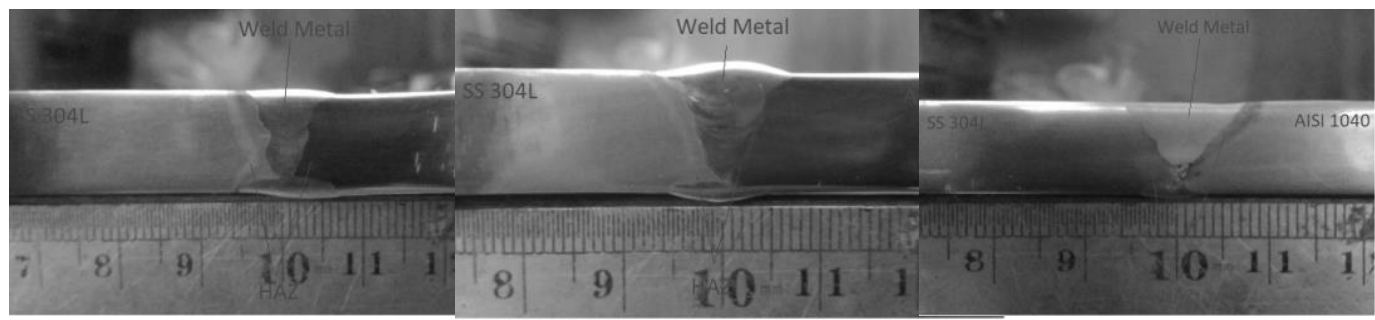

(a)

(b)

(c)

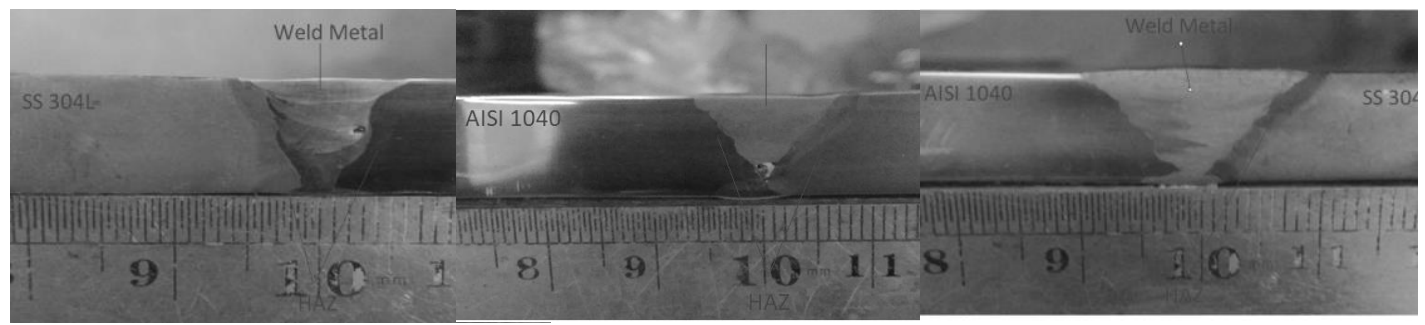

(d)

(e)

(f)

Fig. 8. Macrostructure of dissimilar welding using ER 308L-16 filler metal with V-groove angles (a) $30^{\circ}$, (b) $45^{\circ}$, (c) $60^{\circ}$ and using ER 70S-6 filler metal with V-groove angle (d) $30^{\circ}$, (e) $45^{\circ}$, and (f) $60^{\circ}$.

\section{Conclusion}

The 304L stainless steel and AISI 1040 carbon steel were joined by Gas Tungsten Arch Welding in different welding parameters in this research. The mechanical property and microstructure of the dissimilar joint are studied in detail. The following conclusion can be drawn, the highest tensile strength of dissimilar joint was obtained by joining using ER 308L-16 filler metal with $60^{\circ} \mathrm{V}$-groove angle of $614.54 \mathrm{MPa}$ and $23.89 \%$ elongation that means high strength and ductility was obtained because of the filler metal has low carbon content so it fits for the joining process of dissimilar welding. Low carbon content of filler metal can avoid the forming of precipitation of iron carbides in the dissimilar welding of stainless steel and carbon steel.

Authors would like to thank the financial support (grant number 077/SP2H/LT/K7/KM/2018) from the Ministry of Research, Technology, and Higher Education of The Republic of Indonesia.

\section{References}

1. J.A. James, R. Sudhish, Procedia Technology, 25,2016:1191-1198(2016). https://www.sciencedirect.com/science/article/pii/S2212017316305928

2. X. Yuan, L. Chen, Y. Zhao, H. Di, F. Zhu, Journal of Materials Processing Technology, 217:278-285(2015). https://www.sciencedirect.com/science/article/pii/S0924013614004518

3. A.K. Gupta, H.N. Krishnamurthy, Y. Singh, K.M. Prasad, S.K. Singh, Mater. Design, 45:616-627(2013).

https://www.sciencedirect.com/science/article/pii/S0261306912006723 
4. X.Y. Wang, D.Y. Li, Wear, 255,7-12:836-845(2003). https://www.sciencedirect.com/science/article/abs/pii/S0043164803000553

5. B.R. Kumar, S. Sharma, B.P. Kashyap, N. Prabhu, Mater. Design, 68:63-71(2015). https://www.sciencedirect.com/science/article/pii/S0261306914009960

6. N. Arivazhagan, S. Singh, S. Prakash, G.M. Reddy, Mater. Design, 32,5:30363050(2011). https://www.sciencedirect.com/science/article/pii/S0261306911000550

7. B.-M. Lei, V.-X. Tran, S. Taheri, J.-C. le Roux, F. Curtit, M. He, et al., Int. J. Fatigue, 75:57-68(2015).

https://www.sciencedirect.com/science/article/pii/S0142112315000304

8. H. Ma, G. Qin, P. Geng, F. Li, B. Fu, X. Meng, Mater. Design, 86:587-597(2015). https://www.sciencedirect.com/science/article/pii/S0264127515301374

9. P. Marashi, M. Pouranvari, S. Amirabdollahian, A. Abedi, M. Goodarzi, Materials Science and Engineering: A, 480,1-2:175-180(2008). https://www.sciencedirect.com/science/article/abs/pii/S0921509307014104

10. D. Luder, T. Hundhausen, E. Kaminsky, Y. Shor, N. Iddan, S. Ariely, M. Yalin, Eng. Fail. Anal., 59:292-303(2016).

https://www.sciencedirect.com/science/article/abs/pii/S135063071530114X 